\title{
Reflections on university teaching in China: A personal narrative inquiry
}

\author{
Shuling Li \\ Greg Shaw \\ Shaanxi University of Science and Technology, \\ Xi'an, People's Republic of China \\ vicky0865@126.com \\ greg.shaw@cdu.edu.au
}

Keywords: university teaching and learning, comparative education, culture and learning, narrative inquiry

\begin{abstract}
University teaching academics who want to better understand and develop their teaching for improved student learning can often benefit from experiences in a completely different culture and setting. When university academics travel to another country and participate in teaching there they are often confronted with challenges to their assumptions and approaches to teaching. This paper explores through a narrative enquiry approach the cross-cultural experiences of two university lecturers; one from China and one from Australia. Through their stories here and their reflections on these and reflection on literature they examine their beliefs and practices, and through this try to better understand the assumptions that they hold and how to challenge these in order to be better teachers. The paper provides some other insights into teaching and learning practices within Australia and within China and in particular how the significant changes of higher education in China are both having impact on teachers and learners and are requiring changes of both teaching and learning approaches, Finally, in sharing these experiences the authors provide an opportunity for the reader to similarly engage in processes of personal reflection, and they open up the possibility for other dialogues in this Learning community.
\end{abstract}

\section{Introduction}

All over the world university teaching and learning has undergone significant changes since the last century. Such change is an international phenomenon, though some countries have experienced quite dramatic changes while others have undertaken very little change. Some are still using approaches common over a century ago. In this article a Narrative Inquiry approach (Trahar, 2009) is used to explore differences and similarities of approaches to university teaching and learning in a Chinese and an Australian university. This paper is primarily based upon stories of our experiences and our reflections on these, in an attempt to better understand the contexts in which we work and our practices and the practices of our colleagues.

Shuling's experience as a university teacher over the last 24 years provides her with an opportunity to consider the changes that have taken place in university teaching in China, particularly in English language teaching where she works. In addition to her experience as a teacher at university in China, she recently had the opportunity of a one-year visiting scholar experience in Australia, which allowed her to observe and experience teaching and learning in that context and also to reflect upon her own practices and the practices of her institution. 
Greg has had 26 years' experience working in an Australian university and has also gained some experience of university teaching and learning in China over the last 15 years as an adjunct professor in two institutions.

This paper provides a critically reflective opportunity using Narrative Inquiry to investigate and comment upon contemporary university teaching and learning in China. The paper also makes some comments about lessons that can be learnt from practices in both Chinese and Australian contexts. Additionally, it also provides us with opportunities to think further about our work as university teachers and how we can further develop our practices and also help others who are working in our institutions to think more broadly about our teaching and learning practices.

\section{University teaching in China}

As is well known, China is a large country with an extremely large population - over 1.37 Billion people. With university admission quotas booming since 1999, student numbers have increased rapidly. By the end of 2012 there were over 2,500 universities and colleges in China, with more than six million new enrollments and nearly 24 million enrollments in total (China Statistical Yearbook, 2013). Over $60 \%$ of Chinese high school graduates go on to university study, which is up from $20 \%$ in the 1980 s (The New York Times, 2010). Undergraduate and graduate student numbers from Chinese universities are increasing at approximately $30 \%$ p.a. since 1999 with the number of university graduates quadrupling between 2002 and 2008 ( $\mathrm{Li}$, et.al., 2008), and under the current policies and trends this shows no sign of abating.

This boom in graduates in higher education in China has helped provide skilled professional labor for the developing and growing economy. However, for society generally, significant issues have also emerged because of this boom. First, there is evidence of a qualification creep linked to graduate unemployment across many sectors in China. The strong economic development of China continues; however, the number of graduates of universities has outpaced generally the number of jobs available to them. In the past, a bachelor degree may have been quite adequate for employment in a well-placed job. However, increasingly because of the number of bachelor degree graduates, employers are taking the better graduates or graduates with master degrees. Thus, there is increased pressure on graduates to continue on to a master degree in order to be able to get a job. These days though even having a master degree is not the automatic guarantee of an appointment in a favorable position that was the case only a few years ago. We are starting to find a situation where graduates with master degrees have to take lower level appointments or take positions in 'unfavorable' rural and isolated areas, and some graduates are not able to get employment (Kuo, 2013).

The second issue is that with increased numbers attending universities and limited growth in the numbers of universities, program numbers and class sizes have increased dramatically. Academic staff numbers in universities have increased as well, however, academic staff increases have generally not kept pace with the growth in student numbers, and therefore there has been an expansion in individual teaching workloads. Increased workloads and increased student numbers have required some adjustment to pedagogy used. However, many teaching at Chinese universities follow a 'traditional' lecture and transmission model approach (Van Dijk, et.al., 2002).

Universities, and the staff teaching in them are under pressure to increase the number of graduates, and increase the quality of student learning. Additionally, as Chinese universities strive to gain international recognition, university teachers are under pressure to increase their own academic standing, such as through research and research publication particularly in international journals and conferences (Mohrman, 2008). 
As a university teacher in her institution Shuling is expected to improve her own practices and help other colleagues improve their practices to achieve better outcomes for the department and the university. These outcomes include teaching more students, improving teaching practices, improving their own academic qualification and increasing publication outputs. In order to help facilitate improved quality of university teaching the Government provides funds for staff to upgrade the qualifications and to gain experiences, knowledge and skills. These new skills and knowledge can then be passed on and be of benefit to other staff and students. Shuling recently received a one-year scholarship provided by the China Scholarship Council to visit an Australian university as a Visiting Scholar for a year. The idea of the scholarship was to provide her with a sustained period of time to undertake learning and research and have experiences within an Australian university context that she could then draw upon, learn from and apply to her own teaching as well as to share with colleagues.

Greg is a senior university academic having worked in Australian universities for over 26 years. $\mathrm{He}$ has also worked in China as an adjunct professor, and is a member of a Chinese research Institute based in Beijing. Greg's work in China has involved him regularly with teaching undergraduate as well as postgraduate classes. He has also worked with staff in both these institutions in developing their research and teaching capacity.

\section{A critically comparative Narrative Inquiry approach}

Research in education can generally be classified under two broad categories: quantitative research and qualitative research (Ary, et.al, 2010, p22). In China, quantitative research is by far the dominant paradigm in education. However, increasingly qualitative research approaches are being recognised. Qualitative research is about trying to understand the details of phenomena. It is about trying to understand the meanings and nuances of what is going on. It is not about numbers and statistical analysis but is about the meanings and understandings that people apply to the world as they see it.

Narrative inquiry assumes that we can come to an understanding, and express and give meaning to our lives through stories (Andrews et.al, 2008). Narrative inquiry draws upon hermeneutics and phenomenology and involves gathering of narratives (written, oral, visual) that are focusing on the meanings that people give their experiences, seeking to provide "insight that (befits) the complexity of human lives" (Josselson, 2006, p.4). Narrative inquiry is inherently personal and it is conducted from the perspective of people and their stories. In the case of this research paper it is conducted from our perspectives. Therefore, the research and the reporting of it here is primarily from a first person perspective, which is typical (Said \& Zhang, 2013, p.221) of this academic genre.

The research that this paper describes involved us each engaging in the process of developing 'narratives' based on our experiences as teachers at university. Either concurrently with the development of the narrative or subsequently we have engaged in processes of critical selfreflection. In part these reflective processes were assisted by conversations with others; with colleagues and peers, and with other university academics.

Shuling as a visiting scholar first engaged in a process of attempting to articulate, in writing, her understanding of her perceptions and also her recollections of her experiences. Having collected this writing she further developed her understanding of her views through the discussions that she had with others that helped her to challenge assumptions and in this activity she engaged in processes of critical self-reflection. A reading program that she undertook also assisted this process of critical self-reflection. 
Having the luxury of one year at a university as a 'scholar' and without having administrative or teaching responsibilities provided her with some wonderful opportunities to engage in reading literature. However, the engagements of her inquiries led her into researching other literature that could help her understand and provide meaning. This rich journey of engagement across a whole range of literature that she had not had previous opportunity to access, nor had the time nor inclination to read, opened her mind to both a greater understanding of teaching and learning and education in general, and also raised more questions. The more she read the more she realised she needed to read more.

\section{Shuling's reflecting and learning}

My reflections began soon after my arrival in Australia:

When I first arrived at the university I was both curious and confused at what I saw and felt. Many things were different to my previous experiences, and I had some problems matching my expectations based on my experiences in China. For example, I desired to take photos of the university gate but I could not find 'a gate' like we have in China, where universities typically have walls around them and a defined gated entrance. When I looked for shops on campus to buy my daily necessities and food, there was none. The whole campus was extremely quiet at seven in the evening. Even the architecture was different. Most of the buildings were oddly-looking, neither cube-shaped nor rectangular block. The tallest building on campus was no more than four levels and some looked a little shabby outside, but the university seemed well equipped and spacious inside and out, though I thought it was hard for any strangers to find their way around easily. (From reflective Journal)

I was unfamiliar with the environment that I had come to. At first this unfamiliarity was with the physical environment, but as time went on other aspects of the teaching and learning environment contrasted with my experience.

The university was located in a moderately sized regional town and provided research and education services to the state (province). The university serviced an extremely large area comprising one fifth of the total landmass of Australia, but beyond that the university had substantial student numbers coming from all across Australia and also from overseas. In China nearly all students attend university full-time on campus, and live in dormitories on campus. Face-to-face attendance at classes is compulsory. However, this is not the case in Australia. At my Australian university over $70 \%$ of the students were not located in the town of the university and consequently could not attend face-to-face classes. The university has developed an alternate to face-to-face teaching using Internet based technology and other approaches. I found this very difficult to understand. My own experience as a student then subsequently as a teacher at university presented such a contrast in teaching modes compared to this Australian university. I could not understand how students could effectively learn if they were not in a physical classroom and listening to and interacting with a teacher face-to-face. As an English teacher, being able to hear and see students and provide feedback on their responses is important to me. Additionally, I could not understand how it was possible to 'trust students' that they were actually paying attention and learning.

In order for me to come to a better understanding of what was going on in these 'classes' that were taught at-a-distance, I attended several sessions presented by a number of different lecturers. This required me to use my computer to log-onto to a Learning Management System (LMS) that was used for the interface between students and teacher. The LMS allowed text 
communication, audio communication and video communication between the participants over an Internet connection. Activities in these classes typically comprised a lecturer presenting some information, raising questions, and requiring students to engage in 'discussion' either using the audio/video feature and/or a texting box similar to what might be used in social networking software. In addition, within this LMS the lecturer had placed articles and texts and other information online that the students were expected to access and read. There were also exercises and activities located in this space that students were expected to complete, some of these being part of students' assessment.

One of the things that struck me with this online learning approach was that participation ('attendance') in most cases was not compulsory. Indeed, of all the classes that I observed less than half of those students actually enrolled in the course attended timetabled class sessions, and yet some of these students went on to successfully complete all of the assessment tasks and were allowed to pass the course. Much of the learning that was taking place was occurring outside of the actual 'class' experience. I found this disturbing because my own experience and my beliefs, and these practices were certainly not the practices of my own university.

In addition to observing and experiencing online teaching and learning, I participated in a number of face-to-face classes on campus. I also had the opportunity to observe students on campus and their behaviour in and out of class.

Students' behaviors surprise me. They are free to come and go during class hours. Some wear slippers or flip-flops with boys wearing shorts and girls wearing spaghetti strap blouses. Some middle-aged or even gray-haired students are on the campus studying for a Bachelor's Degree and this is hardly seen in Chinese universities where people in their thirties are rarely seen doing undergraduate study except for some special training programs. (From reflective Journal)

The Australian university has about 25,000 students. However, since a large percentage of these are studying at-a-distance the actual number of students that might be expected on campus would be about 7,000 . Additionally, approximately $65 \%$ of the students are undertaking the course of study part-time, and many of these were mature age, with families and were already in employed work. There never seemed to be a large number of students on campus. This was unexpected. At my own university during a teaching semester the campus abounds with students and just like at my own university there are student amenities such as a cafeteria, coffee shops, post office, a bookshop, medical center and gymnasium and also a student club. However, at my university in China there are many more of these amenities including, canteens, banks and coffee shops, supermarkets, a gymnasium, a post office, some bookshops and bakeries, small shops selling snacks and grocery, a hospital for both students and staff, several outdoor public sports facilities, several printing houses, many newsstands. Just as is in China, students in Australia were seen frequenting on campus venues, although sometimes there seemed to be more staff than students at these facilities.

Face-to-face class activity also had some familiar as well as some quite unfamiliar elements to them. As is indicated by my extract above I was quite taken aback by the dress codes and behaviors of students. Students dressed very casually, and some as if they were going to the beach or a party rather than attending classes. Even some teaching staff dressed very casual and I did not consider this very 'professional'. This was different to my experience where students are expected to dress to certain standards, even if the standards are not written down. Female students are expected to be quite reserved in the dress code and both males and females are expected to be neat and tidy. At my university most staff dress in very 'professional' ways wearing formal business attire reflecting what I believe to be the professional standard of a university lecturer. 
It was not only the ways in which students and staff dressed that disturbed me but a more general sense of informality that seemed to reflect the culture and the environment of the institution. I observed that often some students came late to class. At my university in China this is frowned upon and students are usually disciplined if they do come late - but in any case it infrequently happens. However, in Australia it was typical for students to wander in after the class had started, and even leave during the timetabled class or prior to the class finishing. Although, I did note that some students had at least the courtesy of letting the lecturer know that they were leaving. Also, the Australian academics did not mark an attendance roll. At my Chinese university this is a formality observed in every class at the beginning and or at the end of the class, where class attendance is noted in a formal roll and students who do not have permission to be absent need to provide a reason for that absence to the lecturer with the attendance records collected by the department head. In my university class attendance is a critical and essential part of the university learning experience and indeed constitutes part of the assessment. Students that do not attend classes are unable to pass that course, whereas in Australia attendance was more often not compulsory. Such considerations of attendance may also reflect differences that I observed in teaching practices and pedagogy.

Besides differences in teaching practices and pedagogy, there are also some similarities. In both universities academics prepare course outlines, which indicate the learning outcomes to be achieved, assessment tasks to be completed and assessment requirements and an indication of the content to be covered. The teaching academics in the Australia university were generally well prepared for their teaching, as are my colleagues at my home university. However, this preparation is somewhat different.

In the Australian university, as I have indicated, an LMS is used as a place for academics to locate information about the course as well as content and links to content on the Internet. Preparation then requires the academic to prepare, develop and collect materials and locate these within this LMS space sometime before the class is actually taught. The content, by and large, is not central to the actual 'class' teaching, but students are directed to this as a part of the course experience and are expected to engage in it. However, at my university lecturers prepare an outline of the course to be covered indicating the assessment details etc. and an overview of content. The actual content though is taught during the class sessions and students are expected to take notes. Occasionally, handouts of printed material are also prepared and distributed in class. Often these materials come from courseware available on CDs for teachers that are attached to textbooks. Content presentation is a central part of class activities at my university.

There were also differences in approaches to teaching and techniques used. Within my university the face-to-face class is the central and dominant location of teaching, whereas in Australia, the online LMS is used, 'teaching' takes on a broader form. Because of the limited time available and the amount of content to be covered Chinese university classes tend to be more often information presentation sessions. However, in my English classes in addition to the presentation of information I also allocate time for activities, particularly to practice spoken English following forms and models that I introduce. The Australian university classes that I observed, while they did have some information presentation, tended to have more time to class discussion and student responses.

One feature of the learning environment and culture, that was different across the two institutions was that in Australia students seem to be more willing to engage in discussion than my Chinese students, to make comments, and to raise questions and issues, even at times questioning or taking counterpoints to those of the lecturer. This rarely happens in China where the teacher is held up in respect of his or her knowledge and it is the teacher that is 
expected by the students to hold the knowledge and transmit this knowledge, whereas in Australia there seems to be a greater focus on knowledge generation by the class with the teacher's role being more the facilitator.

\section{Greg's reflections and learning}

I have been doing work in China since about the year 2000. On many occasions I had the opportunity to undertake teaching activities in the various universities that I visit, or that I have an adjunct position with. I am by nature a teacher. I began my career as a high school teacher and I guess many of my teaching characteristics have been formed by this experience and also by my own experience as a learner in school and at University. I have noticed a shift in teaching and learning in China over the last 15 years, which I think to some extent reflects the opening up of China and the increased access that Chinese have to international ideas and yet, there are still stark differences between the teaching and learning cultures of China and what I experience in Australia. I would characterise these differences as mainly being variances in the way that students interact with their teacher and with each other. In China it is nearly always difficult for me to get students to spontaneously ask questions, or to engage in a free flow and open discussion. This is less the case with graduate students but the issue still exists.

Recently I had the opportunity to teach a graduate class. This was quite a different experience in many ways. I undertook the graduate class with a small group of Masters of education students located in a western China University by using the software Skype. Every week we would connect for a one- to two-hour tutorial. I set readings and an outline of topics to be covered, and used the tutorial time to highlight key issues and to have students report on their reading and interact with me and each other through discussion. Initially, it was extremely difficult to get the class to engage and it took all of my skills of coercion and questioning to achieve this. One of the difficulties was the awkwardness that students experienced in working in English as a second language, and I think probably also their not being used to this approach to teaching, the technology, and also the pedagogy that I modelled. Through our discussions they indicated that they were more used to a face-to-face class where the "professor" dominated and delivered content. They were not used to themselves having to take on a major role within the learning environment and to present content through their discussion around their readings. Despite working with this group for a whole semester, and even visiting them on several occasions before and during this teaching event, they never really made the adjustment to a dynamic learning community centred on a social constructivist pedagogical approach (Richardson, 2003).

In dealing with this situation both I and the students made adjustments. Some of these adjustments related to the technology but primarily the adjustments related to their adjustments to learning and my adjustments to teaching. I was constantly reminding myself of the issues that they were trying to deal with. Reading academic articles in English around terms and issues that in most part were new to them, their struggle with communicating in English and then their struggle with coming to grips with this strange professor from Australia who kept on asking them their opinion and ideas. Over the semester subtle adjustments occurred. Their English improved, my Chinese did not. Yet more importantly they started to learn how to learn, to have free-flowing conversations and interactions, even though they still had some way to go in this. 


\section{Issues}

Since the 1990s, there has been increased empirical research on teaching and learning within Confucian-culture backgrounds (Watkins \& Biggs 1996; Watkins \& Biggs in 2001; Chan \& Rao in 2009). These, and many other publications are helping our understanding of the differences in learning environments and pedagogical approaches between Chinese and Western contexts. However, the research has been dominated by studies in Hong Kong and other non-mainland Chinese contexts. Little attention though has been given to understanding the impact of culture on learning environments and comparing Chinese and western university teaching and learning contexts.

\section{Learning environments}

The concept of learning environments is important and basic preconception of many learning theories, and it is particularly important under constructivist learning (Duffy, et.al., 2012). Some writers described learning environments as incorporating physical (constructed elements) (Skill, \& Young, 2002), historical, cultural, and political and ideology components (Sleeter, 2012), as well as incorporating the ecology of the learning environment including student characteristics of school social system and the culture in which it is embedded (Wilson, 1995).

Other scholars define the conception of learning environment directly. Hiemstra defines a learning environment as "...all of the physical surroundings, psychological or emotional conditions, and social or cultural influences affecting the growth and development of an adult engaged in an educational enterprise" (1991, p. 8). Also similarly Fraser states: 'Learning environment refers to the social, psychological and pedagogical contexts in which learning occurs and which affect student achievement and attitudes' (1998, p. 3).

In more recent years, and as is evident from some of the description above the concept of learning environments now comprise virtual as well as physical spaces. "The "spaces" where students learn are becoming more community-driven, interdisciplinary, and supported by technologies that engage virtual communication and collaboration" (Johnson, et.al., 2010, p. 4). ICT and the Internet are increasingly playing a central role in university teaching and learning (Jamil \& Shah, 2011).

For some time two distinct modes of university education were recognised: on-campus and off-campus modes. However, recently the concept of blended learning is increasingly being recognised and actively addressed within pedagogical approaches (Bonk \& Graham 2012). Blended learning involves teaching and learning activity that include both face-to-face and at a distance teaching and learning. While there has always been an aspect of 'blended learning' in any university learning experience - in that students engage in learning outside of the classit is only recently that educationalists plan explicitly to use blended learning approaches. This involves adaptation of existing distance education approaches with the use of the Internet and ICT.

Learning is something that happens within an individual and normally only happens when an individual is inclined towards learning. While learning can occur in a range of environments and can happen under a range of approaches, there are optimal environments and approaches that have been identified. The relationship between optimal learning environments and effective learning are well established. Effective learning environments have a strong connection to student achievement (Harrington \& Enochs, 2009; Ellis, 2005; Biggs, 1994 \&1996) and to student motivation (Busse \& Walter, 2013). 


\section{Culture and learning}

As we engaged in processes of critical reflection we tried to understand our cross cultural experiences and contrast these with our experiences and professional work in our home culture. We came to realisations that culture is fundamental to not only our own beliefs and practices but also to those around us, staff and students.

Bull (2005, p. 167) states "Culture is not only the way we do things. It is our attitudes, thoughts, expectations, goals and values. It is the rules of our society the norms that tell us what are acceptable and not acceptable in our society." Our own beliefs and practices were formed and informed by our own cultures and experiences. For Shuling this includes her broader culture of being brought up as a Chinese citizen, and experiencing a formal Chinese education that drew its roots from Marx's and Lenin's philosophical position, and her informal cultural education through her life experiences in Chinese society, where the norms and values, while also drawing to some extent on Marx's and Lenin's philosophical positions, also draw upon Confucius ideologies beliefs and practices.

In a general sense, social norms tell us which of our actions are permissible. Social norms keep our daily lives in an ordered and patterned existence (Zhang, 2005, p. 237). Social norms are also described as "expectations for proper behavior" and "typical behaviour that is considered appropriate" (O’Donnell, Reeve \& Smith, 2012, p. 195). As such, the social norms that we hold within the society in which we live guides us in what are appropriate or inappropriate behaviors. For both of us, Shuling and Greg, we carried our social norms into our professional practice, and in both cases these were contrasted with the experiences that we had.

Cross-cultural research over the last couple of decades has contrasted the culture and social norms between East and West cultures. Four contrasts can be identified from this research. The first is individualism versus collectivism. Hofstede $(1980 ; 1986 ; 1991)$ develops a fourdimensional model of cultural differences and collectivism versus individualism is one of them. Many researchers recognise China as a collectivistic culture, which sees harmony as having the utmost importance over anything else, and Australia is seen as an individualistic culture (Zhang, 2005, p. 33).

The second contrast is modesty versus self-assurance. Modesty, as a virtue, is highly valued in China. Zhang (2005) suggests that modesty is a universal quality of human beings and it is regarded as one of the factors that lead to success in Chinese society. Bond (1994, pp. 4146) concludes generally that Chinese culture gives more attention to modesty than typically occurs in Western cultures. In Chinese culture, being modest is often a way to show respect to others. So it is not surprising to find that many Chinese students in Western classes have introverted personalities, which sometimes clashes with the pedagogy and what their Western teachers want.

The third contrast is shame versus guilt. Cheung (1986) lists this as a popular distinction between Chinese and Western cultures, commenting that Chinese society is shame-oriented. Yeung and Tung (1996, p. 57) observe that Western societies, influenced by Christianity, operate on the basis of guilt. Zhang (2005, pp. 37-38) notes a difference which lies in "... how the members of the two cultures perceive self and others; the Chinese people are more concerned about how they are viewed by others. Therefore, there is a greater degree of face saving effort than in individualistic societies such as Australia."

The concept of 'face' or 'mianzi' in Mandarin is often roughly translated as 'honor, respect, prestige and reputation', but in fact, it is more than all these. Ting-Toomy (1988, p. 215) defines 'face' as "a strategy that protects self-respect and individual identity." In China, people always 
put high value on saving 'face' and maintaining 'face' remains at the very core of a person's being. On the other hand, loss of 'face' will be avoided at all costs to save individual and family humiliation. So typically Chinese students will strive to avoid loss of 'face', both theirs and others. This explains why Chinese students more often ask clarifying questions rather than taking controversial positions or challenging their teachers' authority.

The fourth contrast is effort versus ability. Under the influence of Confucian philosophy, Chinese culture emphasises endurance, hard work and great effort (Yang, 1986), and Chinese people typically consider that these virtues lead to academic success (Watkins \& Biggs, 2001).

Teaching is a cultural activity. It occurs within cultural complexity and requires sophisticated use of language, which is also culturally bound. Therefore, in order to optimise teaching and learning it is critical to have understanding and appreciation of the cultural context in which it occurs (Chan \& Rao, 2009, p.172; Biggs, 1996b).

\section{Examination orientation}

In Chinese culture formal examination is a key component of education. This is in part derived from the Imperial Examination System established in the seventh century. National examinations dominate the Chinese school system, and teaching and learning are centred on achieving success in these examinations (Lewin \& Lu, 2012). Because of the dominance of examination, teaching and learning in schools tends to be driven by the examinations. There is a general focus on information delivery, on content cramming and on mastering examination techniques (Huang \& Chen, 2008). Chinese students learn knowledge acquisition while students in Australia have a greater focus on problem solving.

\section{Shuling's culture, practices, and thinking}

My teaching practices and beliefs about education have been formed by my own experiences and my culture. My current practices are focused on helping students learn English and so I have a high level of focus on skills acquisition. Reading, writing and translation tasks dominate the English curriculum that I teach and there is an emphasis on grammar, whereas listening and spoken English activities are not strongly represented. While students get a good grounding in English they do not necessarily have a good grounding in applied English and in understanding the cultural contexts that English is evolved from and used in. While I believe, and it is my experience, that my teaching is efficient, I am not convinced that a depth of understanding is achieved in the student learning. One reason for this is the examination processes that we use, which tend to be paper-based, summative and 'academic'.

English as a second language teaching in Australia uses similar approaches and techniques to those that I use. However, constructivism is a dominant educational pedagogy that is used in Australia and in Western educational context generally. Chan (2001, pp. 181-203) examines the effects of constructivist instruction, popular in Australia, on Chinese students' learning and understanding. She indicates that the different constraints imposed on teachers by the educational contexts limit their beliefs and practice. Because of the focus on examinations in China, I have to make sure that my students still perform well in their examinations. As a result of my scholarship and my observations of constructivist approaches used in Australia I now better understand the educational advantages of this approach. However, it would be difficult for me to implement constructivist approaches in the same way at my university, as there is still a high level of incompatibility with the cultural beliefs and practices of my colleagues and the institution. Chan notes: 
For whatever instructional innovations, teachers play a pivotal role in the instructional process. If the approaches were implemented without teachers' understanding, it (the practice) would not work whether it is based on the Eastern or Western traditions (2001, p.198).

Teaching is about achieving student learning. If our goal is to have good teaching then we need to be focused on effective learning and to do this we need to consider the student, their ways of thinking, their previous experiences, and their cultural expectations.

However, what is understood as 'good teaching' varies across cultures as well. British students describe a good teacher as "...to arouse the interest of students, explain concepts clearly, use effective instructions, and organise activities" (Jin \& Cortazzi, 1998, pp.740-756). Whereas some Chinese students describe a good teacher as: "...the ability to deliver a high quality lecture distinguishes a good teacher from a poor one;" and also, a good teacher has "... a wellprepared and clearly structured presentation with the intent to help learners understand the content step-by-step, has deep knowledge, is able to answer questions, and is a good moral model" (Chen \& Bennett, 2012, p. 684).

\section{So what does this mean?}

It is rare in our work as university teachers that we have the opportunity to take time out to think about what we do. A packed timetable, large classes and structured programmes and curriculum dominate our lives as university educators. Having time to observe practices in another institution in another country with opportunities to critically reflect upon our own practices has been extremely positive for us. It has helped us to strengthen our understanding of teaching and learning, of learning cultures and environments and what really is important as opposed to our culturally ladened assumptions. Our initial experiences in different countries and different institutions with different cultures were quite confronting. However, this confrontation, including engaging in scholarship has helped us further think about our own practices and those of our colleagues.

In terms of university teaching Chinese universities have, by and large, followed Western models. Indeed, Chinese universities in many ways are similar to universities found in other countries, particularly as China continues to internationalise Higher Education. Chinese universities have followed international curriculum and pedagogical approaches, though typically these changes have lagged significantly in time behind those of leading universities in the west. Pedagogical approaches in Chinese regional universities have not changed a great deal for decades, and it is in this area that we believe some of the most significant changes will occur and need to occur. The culture of higher education currently practiced in China is deeply embedded in both staff and students, and also more broadly in the community. Changing culture is difficult and takes time.

What is more important from our perspective is that engaging in a cross-cultural professional experience, and then in a process of critical reflection on this experience, articulating this through a narrative inquiry, has helped us to examine our own beliefs and practices, and to begin our own processes of culture change. As we are able to share these experiences with others and compare and contrast our experiences so we engage in a learning community, or a community of professional practice in which we can all learn. Surely such an outcome presents not only opportunities and benefits for us (Shuling and Greg), but also for others. Well we hope so. 


\section{References}

Andrews, M., Squire, C. \& Tambokou, M., (Eds.) (2008). Doing narrative research. London: Sage.

Ary, D., Jacobs, L.C., Razavieh, A., \& Sorensen, C. (2010). Introduction to Research in Education. USA: Wadsworth Publishing.

Biggs, J.B. (1994). What are Effective Schools? Lessons from East and West. Australian Educational Researcher, 21(1), 19-30.

Biggs, J.B. (1996a). Learning, Schooling and Socialization: A Chinese Solution to a Western Problem. In S. Lau (Ed.), Growing Up the Chinese Way (pp.147-167). Hong Kong: The Chinese University Press.

Biggs, J.B. (1996b). Western misperceptions of the Confucian-Heritage learning culture. In D. A. Watkins \& J. B. Biggs (Eds.), The Chinese Learner: Cultural, Psychological and Contextual Influences (pp.46-66). Hong Kong/Melbourne: Comparative Education Research Centre, The University of Hong Kong/ Australian Council for Educational Research.

Bond, M.H. (1994). Continuing Encounters with Hong Kong. In J. Lonner \& R. Malpass (Eds.), Psychology and Culture (pp.41-46). Boston: Allyn and Bacon.

Bonk, C.J., \& Graham, C.R. (2005). The Handbook of Blended Learning: Global Perspectives, Local Designs. San Francisco: Pfeiffer Publishing.

Bull, B. (2005). Home and away-cross-cultural communications. In G. Shaw (Ed.), Tertiary Teaching Learning: Dealing with Diversity (pp. 167-176). Darwin: Charles Darwin University.

Busse, V., \& Walter, C. (2013). Foreign Language Learning Motivation in Higher Education: A Longitudinal Study of Motivational Changes and Their Causes. The Modern Language Journal, 97(2), 435-456.

Chan C.K.K. (2001). Promoting Learning and Understanding through Constructivist Approaches for Chinese Learners. In D. A.Watkins \& J. B. Biggs (Eds.), Teaching the Chinese Learner: Psychological and Pedagogical Perspectives (pp 181-203). Hong Kong/Melbourne: Comparative Education Research Center, The University of Hon.g Kong/ Australian Council for Educational Research.

Chan C.K.K. \& Rao N. (2009). Moving beyond paradoxes: understanding Chinese learners and their teachers. In C.K.K. Chan \& N. Rao (Eds.), Revisiting the Chinese Learner: Changing Contents, Changing Education (pp. 3-34). Hong Kong: Comparative Education Research Center, The University of Hong Kong.

Chen, R., \& Bennett. S (2012). When Chinese learners meet constructivist pedagogy online. Higher Education, 64, 677-691. DOI: 10.1007/s10734-012-9520-9

China Statistical Yearbook (2013). National Bureau of Statistics of China. Retrieved from http://www. stats.gov.cn/tjsj/ndsj/

Duffy, T.M., Lowyck, J., \& Jonassen, D.H. (2012). Designing environments for constructive learning. Springer Publishing Company.

Ellis, J. (2005). Place and Identity for Children in Classrooms and Schools. Journal of the Canadian Association for Curriculum Studies, 3(2), 55-73.

Fraser, B.J. (1998). Classroom environment instruments: Development, validity and applications. Learning Environment Research, 1, 7-33.

Harrington, R.A., \& Enochs, L.G. (2009). Accounting for preservice teachers' constructivist learning environment experiences. Learning Environment Research, 12, 45-65. DOI:10.1007/ s10984-008-9053-4. 
Hiemstra, R. (1991). Aspects of Effective Learning Environment. New Directions For Adult Continuing Education. 50, 5-12. San Francisco: Jossey-Bass.

Hofestede, G.H. (1980). Culture's Consequences, international differences in work-related values. London: Sage Publications.

Hofestede, G.H. (1986). Cultural differences in teaching and learning. International Journal of Intercultural Relations, 10(3), 301-320.

Hofestede, G.H. (1991). Cultures and Organizations: Software of the mind. London: McGraw-Hill Company.

Huang, Y.J., \& Chen, C.W. (2008). Academic Cram Schooling, Academic Performance, and Opportunity of Entering Public Universities (Article written in Chinese). Bulletin of Educational Research, 54(1), 117-149.

Jamil, M., \& Shah, J.H. (2011). Technology: its potential effects on teaching in higher education. New Horizons in Education, 59(1), 38-51.

Jin, L., \& Cortazzi, M. (1998). Dimensions of dialogue: Large classes in China. International Journal of Educational Research, 29, 739-761.

Johnson, L., Smith, R., Levine, A., \& Haywood, K. (2010). The 2010 Horizon Report: K-12 Edition. Austin, TX: New Media Consortium.

Josselson, R. (2006). Narrative research and the challenge of accumulating knowledge. Narrative Inquiry, 16(1), 3-10.

Kuo, L. (2013). Welcome to the workforce: A Chinese official tells millions of unemployed new graduates they can only blame themselves, Quartz, Retrieved from: http:// qz.com/111731/a-chinese-official-tells-millions-of-unemployed-new-graduat.

Lewin, K., \& Lu, W. (2012). 12 University entrance examinations in China: a quiet revolution. Changing Educational Assessment (RLE Edu D), 36, 153.

Li, Y., Whalley, J., Zhang, S., Zhao, X. (2008). China's higher education transformation and its global implications, Vox - Research-based policy analysis and commentary from leading economists, Retrieved from: http://www.voxeu.org/article/china-s-higher-education-transformation.

Mohrman, K. (2008). The emerging global model with Chinese characteristics. Higher Education Policy, 21(1), 29-48.

O’Donnell, A.M., Reeve, J., \& Smith, J.K. (2012). Managing Learning in Classrooms. Educational Psychology: Reflection for Action (Third Edition) (p.188). New York: John Wiley \& Sons Inc.

Richardson, V. (2003). Constructivist pedagogy. The Teachers College Record, 105(9), 1623-1640.

Said, S.B., \& Zhang, L.J. (2013). Language Teachers and Teaching: Global Perspectives, Local Initiatives. New York: Routledge.

Sellar, S., \& Lingard, B. (2013). Looking East: Shanghai, PISA 2009 and the reconstitution of reference societies in the global education policy field. Comparative Education, 49(4), 464-485.

Skill, T.D., \& Young, B.A. (2002). Embracing the hybrid model: Working at the intersections of virtual and physical learning spaces. New Directions for Teaching and learning, 2002(92), 23-32.

Sleeter, C.E. (2012). Confronting the marginalization of culturally responsive pedagogy. Urban Education, 47(3), 562-584.

The New York Times (2010). 'The China Boom'. Nov. 5, 2010 
Trahar, S. (2009). Beyond the Story Itself: Narrative Inquiry and Autoethnography in Intercultural Research in Higher Education. Forum Qualitative Sozialforschung [Forum: Qualitative Social Research], 10(1). Retrieved from http://www.qualitative-research.net/index.php/fqs/article/ view/1218/2653.

Van Dijk, L.A., \& Jochems, W.M.G. (2002). Changing a traditional lecturing approach into an interactive approach: Effects of interrupting the monologue in lectures. International Journal of engineering education, 18(3), 275-284.

Watkins, D.A. \& Biggs, J.B. (Eds.). (1996). The Chinese Learner: Cultural, Psychological and Contextual Influences. Hong Kong/Melbourne: Comparative Education Research Center, The University of Hong Kong/ Australian Council for Educational Research.

Watkins, D.A. \& Biggs, J.B. (Eds.). (2001). Teaching the Chinese Learner: Psychological and Pedagogical Perspectives. Hong Kong/Melbourne: Comparative Education Research Center, The University of Hong Kong/ Australian Council for Educational Research.

Wilson, B.G. (1995). Metaphors for instruction: Why we talk about learning environments. Educational Technology, 35, 25-25.

Yang, K.S. (1986). Chinese personality and its change. In M. H., Bond (Ed.), The psychology of the Chinese people. Hong Kong: Oxford University Press.

Yeung, Y.M., \& Tung, R.L. (1996). Achieving business success in Confucian societies. Organizational Dynamics, 25(2), 54-65.

Zhang, Q. (2005). It's More Than a Piece of Paper, Chinese students' experience of learning in Australia. An unpublished doctoral dissertation, Faculty of Education, Health and Science, Charles Darwin University, NT, Australia. 